This is the post print version of the article, which has been published in Journal of Environmental Psychology. 2018, 59, 85-93. https://doi.org/10.1016/j.jenvp.2018.08.014 [2] This document has been downloaded from TamPub.uta.fi

\title{
Restoration, well-being, and everyday physical activity in indoor, built outdoor and natural outdoor settings
}

Pasanen, Tytti P.ab; Ojala, Ann; Tyrväinen, Liisa ${ }^{\mathrm{c}}$; Korpela, Kalevi M. ${ }^{\mathrm{b}}$

aCorresponding author, tytti.pasanen@uta.fi

${ }^{b}$ Faculty of Social Sciences / Psychology, Kalevantie 5, 33014 University of Tampere, Finland

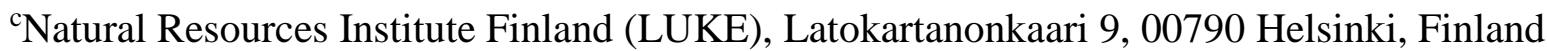

Cite as: Pasanen, T. P., Ojala, A., Tyrväinen, L., \& Korpela, K. M. (2018). Restoration, well-being, and everyday physical activity in indoor, built outdoor and natural outdoor settings. Journal of Environmental Psychology 59, 85-93. doi: 10.1016/j.jenvp.2018.08.014.

\begin{abstract}
Physical activity in natural settings has been found in experimental research to be more restorative than physical activity in built indoor or outdoor settings, yet we lack evidence of this in everyday life. In this study we examined recalled restoration (with the 9-item Restoration Outcome Scale) of the most recent physical activity session in indoor, built outdoor and natural outdoor settings using measurement invariance tests $(n=2577)$. We also compared the relationships between restoration, emotional well-being and frequency of physical activity in these groups. Recalled restoration formed two factors, Restorativeness and Assurance, in all groups, with equal loadings but partly varying item-specific means. Restorativeness was positively connected to emotional well-being in all settings but it did not explain the connection between well-being and physical activity in natural settings. Future studies could explore in more detail how emotional well-being and repeated restoration in different types of environments intertwine.
\end{abstract}

Keywords: restorative environments, green exercise, psychological well-being, physical activity, emotional well-being, measurement invariance 


\section{Introduction}

Contact with nature has consistently shown a positive correlation with well-being (Hartig et al., 2014). A recent synthesis identified three major pathways that explain this correlation: harm reduction (such as less pollution and noise), psychological restoration (attention restoration, stress reduction), and capacity building (such as social cohesion and physical activity; Markevych et al., 2017). These different pathways intertwine and may be mutually reinforcing. For example, natural environments are often conducive to physical activity, known to enhance well-being, and they have also been suggested to bring an added value to the known benefits of physical activity in relation to built indoor or outdoor environments (Bowler et al., 2010; Fox, 1999; Markevych et al., 2017; Pasanen et al., 2014; Thompson Coon et al., 2011). This added value has been explained by experienced psychological restoration, covered by two well-known theories within environmental psychology (Markevych et al., 2017). Ulrich’s stress reduction theory (STR) describes a restorative experience as both psychologically and physically reduced stress (Ulrich, 1983; Ulrich et al., 1991). Kaplan and Kaplan's attention restoration theory (ART) sees stress as depleted attentional capacities which recover and are replenished involuntarily and effortlessly during a restorative experience (Kaplan \& Kaplan, 1989; Kaplan, 1995). However, the majority of the evidence indicating that physical activity in natural settings is more restorative than physical activity in built indoor and outdoor settings is experimental, and observational evidence from restorative everyday experiences is lacking (Markevych et al., 2017). We do not know if restorative experiences through physical activity differ in everyday life when individuals have themselves chosen the activity and its setting.

Restoration is a short-term, mood-like state involving affective, physiological and attention restoration (Kaplan \& Kaplan, 1989; Ulrich, 1983). These different aspects of restoration have been integrated in the Restoration Outcome Scale (Korpela, Ylén, Tyrväinen, \& Silvennoinen, 2008), widely used in empirical research on restorative environments. The scale originally consisted of six items deriving from SRT and ART (Korpela et al., 2008; cf. Hartig, Lindblom, \& Ovefelt, 1998) and it was later extended into a 9-item version based on empirical evidence. The additional items measure vitality (an energetic positive state) and self-confidence (Korpela \& Ylén, 2009), both consistently found to improve after contact with restorative (natural) environments (Barton \& Pretty, 2010; Ryan et al., 2010). Restoration is a multifaceted experience and precise knowledge of the effects of nature on these different aspects would help to better evaluate the contributions of each component in the restorative process. How these additional concepts, vitality and self- 
confidence, relate to and interact with each other and the stress- and attention-related concepts has nevertheless not been examined to date to our knowledge.

The theories and the majority of the applied research on restorative environments have focused on examining natural settings (Ulrich, 1983, Kaplan \& Kaplan, 1991; San Juan, Subiza-Pérez, \& Vozmediano, 2017). The restorative potential of built urban settings has been largely ignored, and often unpleasant urban scenes have been chosen merely to highlight the restorative qualities of nature (Karmanov \& Hamel, 2008; San Juan et al., 2017). As recent evidence suggests that urban settings can also be restorative (Stigsdotter et al., 2017), there is a need to evaluate whether they provide restoration on similar aspects as natural settings. Similarly, the restorative potential of physical activity in indoor environments has been underinvestigated (Hug et al., 2009). Physical activity indoors has become more and more popular in recent decades in Finland, while the share of physical activity in natural settings has decreased (Husu et al., 2011). To assess if and how different types of environments for physical activity support our everyday restoration, we examine recalled restoration after physical activity in indoor, built outdoor and natural outdoor environments.

Both situational and individual factors play a role in what kind of environments we choose for physical activity. Not all physical activity can be conducted in (natural) outdoor settings due, for example, to weather, seasonal variation and lack of facilities. These constraints reflect the activities conducted: the most common activities in indoor environments are gymnastics and swimming, whereas in outdoor environments people prefer to walk, cycle and ski (Husu et al., 2011). Individual characteristics, such as identifying with the natural or urban, influence the types of environments we choose to visit and how restored we feel after visiting them (Morton, van der Bles, \& Haslam, 2017). Furthermore, individuals may use natural and built, indoor or outdoor environments for different reasons and restoration needs (Hartig et al., 2014; Markevych et al., 2017). Having different motives for physical activity such as maintaining physical fitness and reducing stress does not, however, exclude the possibility of experiencing restoration, but restoration may be qualitatively different after physical activity conducted for different reasons in different types of environments (Markevych et al., 2017; Pasanen, Neuvonen, \& Korpela, 2017).

One way to disentangle the potentially different restorative qualities that built and natural environments may support is to assess restoration with more detailed methods. Experimental studies often compute summary scores of different psychometric scales measuring restorative outcomes. Summary scores, even though useful in some cases, can mask differences between the items within a scale by assigning equal weight to each variable (Marsh et al., 2013; Williams \& Boyle, 2008). 
More refined methods that assess the qualities within and between scales, such as structural equation modelling (SEM) have become common in psychological research and their use in environmental psychology has been encouraged (Hine, Corral-Verdugo, Bhullar, \& Frias-Armenta, 2016; Markevych et al., 2017). With SEM we can assess if and how items within a scale intercorrelate and compare the correlative structures between different groups by a methodology known as measurement invariance (Kline, 2016). We use these measurement invariance methods in the first part of this study to explore the qualitative and quantitative differences in restorative experiences after everyday physical activity in different types of environments.

Restorative experiences may be important for our everyday coping and resource management (Hartig et al., 2014). Hence an underlying idea in restorative environments research has been that experiencing restoration (in natural settings) repeatedly supports emotional well-being in the longer-term (Hartig et al., 2014; Markevych et al., 2017). We call this the repeated restoration hypothesis. This idea that recurrent restorative experiences accumulate over time into greater wellbeing has not, however, been properly addressed in past research (Markevych et al., 2017). There is some experimental evidence to suggest that perceived restoration mediates the increase in positive affect followed by exposure to natural rather than urban, virtual settings (McAllister et al., 2017) but similar findings from everyday life are scarcer. Tentative evidence was provided in a study by Korpela et al. (2014), where recalled restoration from the most recent visit to nature mediated the relationship between the frequency of visiting natural environments and emotional well-being. This study, however, was limited to natural settings.

Although the evidence for repeated restoration is so far scarce, we know more about the direct connection between well-being and exposure to natural settings. Residents in greener neighbourhoods constantly rate their mental well-being better than those in less green areas (van den Berg et al., 2015). Similarly, more frequent PA in natural settings (but not in indoor or built outdoor environments) has been associated with greater emotional well-being (Pasanen et al., 2014). Yet the evidence is partly ambiguous. Mitchell (2013) found that regular physical activity in natural environments was connected to a reduced risk of poor mental health, whereas regular physical activity indoors was connected to positive aspects of well-being. One possible explanation for these inconsistent findings could again be that different types of environments induce different types of positive responses (Mitchell, 2013). We know that physical activity in general, regardless of the environment, is moderately related to better emotional well-being (Fox, 1999; Penedo \& Dahn, 2005). This connection is mediated by mood enhancement and increased self-esteem, indicating that the positive effects of physical activity on mood and self-esteem accumulate over 
time into greater longer-term well-being (Fox, 1999). The 'repeated restoration' hypothesis, in turn, suggests that regular physical activity in natural environments is connected to emotional well-being specifically via repeated restorative experiences. Is this connection exclusive to, or stronger, in natural environments than in other settings? This question is the focus of the second part of our study.

Our study makes two main contributions to the research on restorative environments. First, we examine in detail whether restorative outcomes of recent everyday physical activity differ in quantity and/or quality between three types environments: indoor (for example, home or a gym), built outdoor (streets, sports fields) and natural outdoor settings (forests, urban parks). Second, we examine the 'repeated restoration' hypothesis by assessing whether the frequency of physical activity and recalled restoration in indoor, built outdoor and natural outdoor settings are related to emotional well-being in different ways.

\section{Materials and methods}

\subsection{Data}

We used two rounds from the 'Outdoor recreation demand inventory', collected in winter and spring/summer 2009 by Statistics Finland (Sievänen \& Neuvonen, 2011). In these two rounds the survey was sent to a sample of 8,000 randomly selected Finnish citizens aged 15-74 years, drawn from the population registry. With 3,060 respondents, the response rate was 38\%. The response rates were higher for women than men, and younger age groups were underrepresented in comparison to older age groups (Virtanen et al., 2011). However, these biases were relatively small, and the interviewed sample of the non-respondents revealed no differences in the recreation patterns of the respondents and non-respondents (Virtanen et al., 2011). We excluded those respondents who reported physical handicaps that prevented them from engaging in physical activity outdoors. Due to this screening and missing responses, the present analyses included 2,568-2,577 respondents (Table 1). 
Table 1 Sample descriptives

\begin{tabular}{rrcc} 
Variable & Range or category & $\mathrm{n}$ & Mean (SD) or \% \\
\hline Gender & Male & 1164 & 45.2 \\
& Female & 1413 & 54.8 \\
Age & $15-74$ years & 2577 & $45.7(16.2)$ \\
Monthly & $\leq 1000$ & 136 & 5.3 \\
household & $1001-3000$ & 757 & 29.4 \\
income $(€)^{*}$ & $3001-5000$ & 695 & 27.0 \\
& $5001-7000$ & 393 & 15.3 \\
& $>7000$ & 235 & 9.1 \\
& Missing/don't & & 14.0 \\
\hline know/refused & 361 & \\
\end{tabular}

*categories have been combined

\subsection{Measures}

Recalled restoration after the most recent physical activity was measured with 9-item Restoration Outcome Scale where the respondents are asked to rate to which extent each statement describes their experiences (Korpela et al., 2008). According to earlier studies on restoration (Hartig et al., 1998; Staats, Kieviet, \& Hartig, 2003), of the six original items, three measure relaxation and calmness (a, c, and d; Table 3), one attention restoration (b) and two clearing one's thoughts (e and f). Two of the additional items measure vitality ( $\mathrm{i}$ and h) and one self-confidence (g) (Korpela, 1992; Korpela \& Ylén, 2009; Ryan et al., 2010). All items are evaluated on a 7-point scale, with greater values indicating more restoration.

Emotional well-being was measured by the respective subscale in the validated Short-Form Health Survey (also known as the RAND 36-item health survey; Hays, Sherbourne, \& Mazel, 1993; Finnish validations by Aalto, Aro, \& Teperi, 1999). The subscale for emotional well-being consists of five statements, evaluated on a 6-point scale related to respondents' well-being in the past four weeks. Two items measure positive emotional state (e.g. “Have you felt calm and peaceful?”) and three items negative emotional state (e.g. “Have you felt downhearted and blue?”); these were inverted in the analyses so that higher values indicated greater well-being.

The type of environment of the most recent physical activity was used to group respondents into three groups: indoors $(n=592)$, outdoors in natural settings $(n=1188)$ and outdoors in built settings ( $n=752$ ). We excluded the physical activity that took place in one's own front/backyard since we had no information about whether these were built or natural. 
For an estimate of the weekly frequency of leisure time physical activity indoors, outdoors in built settings and outdoors in natural settings, the respondents were asked to estimate the percentage of their leisure-time physical activity that takes place in these three types of environments. These shares were multiplied by the weekly frequency of leisure-time physical activity to gain an estimate of how many times per week the respondents engaged in physical activity in indoor, built outdoor and natural outdoor settings (see Pasanen et al., 2014 for more details).

Age, gender and household income (in thousands) were not of primary interest in this study but they were added as socio-demographic covariates in the sensitivity analyses to ensure that the connections found were not due to these potentially confounding factors. For example, gender, age and income are not necessarily related to emotional well-being (Aalto et al., 1999) but may be associated with the types of physical activity that we engage in, the settings for physical activity we can access and how we respond to these settings (Barton \& Pretty, 2010; Husu et al., 2011). However, their role in the environment-well-being relationship has reportedly been mixed (van den Berg et al., 2015; Markevych et al., 2017).

\subsection{Statistical analyses}

In all analyses the data was grouped according to the location of the most recent physical activity indoors, outdoors in built settings and outdoors in natural settings. The analyses were conducted using Mplus 8 with maximum likelihood estimator with robust standard errors, suitable for continuous, non-normally distributed variables (Muthen \& Muthen, 1998-2012). As our data is relatively large and we conduct multiple tests, we use a 99\% confidence level as the criterion for “statistical significance”. We also examine and report the 99\% confidence intervals (CI) which, in the case of this estimator, are equivalent to the generally recommended bootstrapped CIs (Muthen \& Muthen, 1998-2012).

\subsubsection{Measurement invariance tests}

The items in the 9-item Restoration Outcome Scale comprise different aspects of restoration that are related but separate, and accordingly, exploratory SEM was appropriate (Asparouhov \& Muthén, 2009; Davidov et al., 2014; Marsh et al., 2013). We followed the approach taken by Asparouhov and Muthén (2009; Muthén \& Muthén, 1998-2012) to assess the measurement invariance of the 9item Restoration Outcome Scale responses based on physical activity in indoor, built outdoor, and natural outdoor settings. We examined five types of measurement invariance where each successive model assumes more equivalence (invariance) between the groups (Muthén \& Muthén, 1998-2012). If the added constraints improve model fit, we can interpret that the constrained parameter(s) are 
equal across these groups. In Step 1, we tested the optimal number of factors and whether the same items loaded on the same factor(s) by specifying 1-3 exploratory factors (Korpela et al., 2008, Korpela \& Ylén, 2009) for each group individually but simultaneously. The following models constrained factor loadings (Step 2), item-specific intercepts (Step 3), factor variances and covariances (Step 4) and factor means (Step 5), and tested their equivalence across groups (Muthén \& Muthén, 1998-2012).

We examine model fit and its changes with several recommended criteria: the $\chi^{2}$ test of overall fit, the Satorra-Bentler corrected $\chi^{2}$-difference tests for nested models, a set of recommended fit indices and normalised covariance residuals (|>1.96| considered large) (Chen, 2007; Kline, 2016; Satorra \& Bentler, 2010). All fit indices are based on the $\chi^{2}$ value that has been criticised in the case of both large and unequal sample sizes in measurement invariance tests and hence is interpreted with caution (Chen, 2007). The recommendations for cut-off values that indicate good model fit vary between $\leq .05 / .06 / .08$ for the Root Mean Square Error of Approximation (RMSEA), $\geq .90 / .95$ for the Comparative Fit Index (CFI) and the Tucker-Lewis Fit Index (TLI) and $\leq .08 / .10$ for Standardised Root Mean Square Residual (SRMR; Asparouhov \& Muthén, 2009; Kline, 2016; Rutkowski \& Svetina, 2014). When comparing nested models with different levels of measurement invariance, the model fit is assumed to remain approximately equal if the $\chi^{2}$-difference test is non-significant (p>.01), and the differences in the fit indices are >-.010/-.005 for CFI, <.010/.015 for RMSEA and $<.005-.030$ for SRMR, depending on the type of invariance (Chen, 2007; Cheung \& Rensvold, 2002). With these criteria, we choose the best-fitting model from Steps 1-5 for the second phase of the analysis (Davidov et al., 2014).

\subsubsection{Examining the 'repeated restoration' hypothesis}

Next we specify a multigroup exploratory SEM model with direct relationships between emotional well-being and recalled restoration after the most recent physical activity indoors, outdoors in built settings and outdoors in natural settings, controlling for the weekly frequency of physical activity in that environment. For recalled restoration, we use the factor structure from the previous analysis, and emotional well-being is specified as a latent confirmatory factor with equal loadings and intercepts in all groups.

We examine the following hypotheses: 1) more frequent physical activity is associated with stronger recalled restoration after the most recent physical activity, 2) recalled restoration is positively connected to emotional well-being, 3) more frequent physical activity is connected to better emotional well-being and 4) recalled restoration mediates the relationship between physical 
activity and emotional well-being (Fox, 1999; Markevych et al., 2017). Following the 'repeated restoration' hypothesis, we assume that the association between recalled restoration and emotional well-being (Hypothesis 2) is the strongest in the nature group (Pasanen et al., 2014). We also compared between-group differences in the weekly frequency of physical activity, recalled restoration and emotional well-being. Although our model is a mediation model in which we examine indirect connections (Hypothesis 4), and the theories suggest a temporal order where repeated physical activity sessions lead to greater emotional well-being via repeated restorative experiences (Markevych et al., 2017), with cross-sectional data we can only assess correlational relationships.

\subsubsection{Sensitivity analyses}

We specified four alternative models to ensure that our main results were not affected by misspecifications. First, regarding the 9-item Restoration Outcome Scale, most our estimated models showed two large, unexpected normalised covariance residuals. We re-ran the models allowing the error variances of these problematic items to correlate. Second, in Emotional wellbeing, the residual variance of the happiness item correlated substantially with the residual variance of other items , and we consequently re-ran the model without this item. Third, to see if the positive connections found were not simply due to some groups engaging in physical activity more frequently than others, we ran the models using the total, instead of setting-specific, frequency of weekly physical activity. Fourth, to ensure our main results were not due to potentially confounding socio-demographic factors, we specified one model with gender, age and income as covariates for both recalled restoration and emotional well-being (van den Berg et al., 2015; Markevych et al., 2017).

\section{Results}

\subsection{Measurement invariance of the 9-item Restoration Outcome Scale}

Following the criteria in Section 2.3, the best fitting model was a partially invariant model in Step 4 (Table 2). This model (Table 3) consisted of two factors (Step 1) whose loadings were equal (Step 2), all but three intercepts were equal (Step 3) and factor means varied between the groups (cf. Step 5). Regarding the varying intercepts, calmness (a) was the greatest after physical activity in natural settings, and forgetting everyday worries (e) and gaining self-confidence (g) were the greatest after physical activity indoors. In terms of the factors means, Factor 1 was greater in the nature group than in the built outdoor group, whereas Factor 2 was equal across groups. 
Table 2 Model fits for measurement invariance tests for 9-item Restoration Outcome Scale. The row in bold face represents the best-fitting model.

\begin{tabular}{|c|c|c|c|c|c|c|c|c|c|}
\hline Step & Description & $\begin{array}{c}\chi^{2} \\
\text { value }\end{array}$ & $\mathrm{df}$ & $p$ & $\begin{array}{l}\chi^{2} \text { diff. } \\
\text { test, } p^{*}\end{array}$ & RMSEA & CFI & TLI & SRMR \\
\hline $1 \mathrm{a}$ & Individual models, 1 factor & 1086 & 81 & $<.001$ & & .12 & .89 & .86 & .05 \\
\hline $1 b$ & Individual models, 2 factors & 382 & 57 & $<.001$ & $<.001$ & .08 & .97 & .93 & .02 \\
\hline 2 & Equal loadings & 423 & 85 & $<.001$ & .011 & .07 & .96 & .95 & .03 \\
\hline За & Equal item intercepts & 526 & 103 & $<.001$ & $<.001$ & .07 & .96 & .95 & .05 \\
\hline $3 b$ & Equal item intercepts ${ }^{\mathrm{a}}$ & 460 & 97 & $<.001$ & $<.001$ & .07 & .96 & .96 & .04 \\
\hline 4 & $\begin{array}{l}\text { Equal factors variances } \\
\text { and covariances }\end{array}$ & 448 & 99 & $<.001$ & $* *$ & .07 & .96 & .96 & .05 \\
\hline 5 & Equal factor means ${ }^{\mathrm{a}}$ & 463 & 103 & $<.001$ & .003 & .06 & .96 & .96 & .05 \\
\hline
\end{tabular}

\footnotetext{
* Satorra-Bentler corrected, comparison to the previous model. Significant value: the model with less $\mathrm{df}$ fits the data better

** could not be calculated due to a negative difference in the $\chi^{2}$ values between models 4 and $3 \mathrm{~b}$, . It is, however, evident that model 4 fits the data better because it has greater $\mathrm{df}$ but smaller $\chi^{2}$ value.

a intercepts for items a, e and g freely estimated between groups

Content-wise, Factor 1 represented the original, 6-item Restoration Outcome Scale and we labelled it 'Restorativeness' (Figure 1, Table 3). Factor 2 was named 'Assurance' because items on selfconfidence (g) and gaining faith in tomorrow (h) loaded on it the highest. Item i 'My vitality and energy increased' loaded moderately on both factors (.54-.65). The correlation between the factors was high $(r=.77)$.
}

All 2-factor models (1b-5; Table 2) showed acceptable fit with the data in all criteria except the $\chi^{2}$ test (Chen, 2007). Most analyses showed large normalised covariance residuals between items (a, b) and items (e,f) and we conducted sensitivity analysis to ensure our main results were not affected by these (all residuals, converted into correlation-metric, are provided in Appendix Table A.1). 
Table 3 The factor structure of the best-fitting measurement invariance model (Model 4, Table 2). Estimates in bold face: statistically significant $(p<.01)$ difference from the other group(s), or loading $>.50$.

\begin{tabular}{|c|c|c|c|c|c|c|c|c|}
\hline \multirow[b]{2}{*}{ Item } & \multicolumn{2}{|c|}{ Loadings } & \multicolumn{3}{|c|}{ Estimated means } & \multicolumn{3}{|c|}{ Std. residual variances } \\
\hline & $\begin{array}{c}\text { Factor } 1 \\
\text { Restorativeness }\end{array}$ & $\begin{array}{c}\text { Factor } 2 \\
\text { Assurance }\end{array}$ & Indoor & $\begin{array}{c}\text { Built } \\
\text { outdoor }\end{array}$ & Nature & Indoor & $\begin{array}{c}\text { Built } \\
\text { outdoor }\end{array}$ & Nature \\
\hline a) I calmed down & 0.96 & -0.03 & 4.87 & $5.01^{\mathrm{i}}$ & $5.12^{i, b}$ & .49 & .39 & .41 \\
\hline b) My concentration and alertness increased & 0.94 & 0.06 & & 4.71 & & .36 & .34 & .35 \\
\hline c) I gained new spirit for my everyday routines & 1.04 & 0.01 & & 4.97 & & .30 & .25 & .26 \\
\hline d) I felt restored and relaxed & 1.06 & -0.06 & & 5.00 & & .33 & .25 & .26 \\
\hline e) I forgot everyday worries & 0.74 & 0.31 & $4.94^{\mathrm{b}, \mathrm{n}}$ & 4.70 & 4.76 & .53 & .49 & .49 \\
\hline f) My thoughts were clarified & 0.71 & 0.40 & & 4.70 & & .32 & .30 & .29 \\
\hline g) I became more self-confident & 0.06 & 1.17 & $4.54^{\mathrm{b}, \mathrm{n}}$ & 4.35 & 4.33 & .25 & .22 & .23 \\
\hline h) I gained faith in tomorrow & -0.01 & 1.30 & & 4.49 & & .14 & .12 & .10 \\
\hline i) My vitality and energy increased & 0.54 & 0.65 & & 4.86 & & .24 & .24 & .26 \\
\hline Factor means (99\% CIs) $\quad$ Indoors & $0 *$ & $0 *$ & & & & & & \\
\hline Built outdoor & $-0.02[-0.17 ; 0.14]$ & $-0.08[-0.23 ; 0.07]$ & & & & & & \\
\hline Nature & $0.14[-0.01 ; 0.28]$ & $0.03[-0.11 ; 0.17]$ & & & & & & \\
\hline Difference (built-nature) & $-0.15[-0.28 ;-0.03]$ & $-0.11[-0.23 ; 0.02]$ & & & & & & \\
\hline
\end{tabular}




\subsection{The repeated restoration hypothesis}

As we hypothesised (1), the connections between the frequency of physical activity and Restorativeness and Assurance of the most recent bout of physical activity were positive in all groups, with no differences between the groups (Figure 1; Appendix Table B.1). Similarly, Hypothesis 2 was supported because greater Restorativeness was associated with better Emotional well-being, although contrary to our assumption, this connection was equally strong in all environments and non-significant for Assurance. Hypothesis 3 was supported only in the nature group: after controlling for recalled restoration, Emotional well-being was positively associated with more frequent physical activity in natural settings but not indoors or in built outdoor settings. As for Hypothesis 4, Restorativeness mediated the connection between frequency of physical activity and Emotional well-being in indoor and built outdoor but not natural settings (Table 4).

The model explained 6.8\%-11.4\% of Emotional well-being within the groups (Table 4), indicating a small yet practically meaningful effect size (Ferguson, 2009). The model fit indices were close to those of the measurement invariance model. 'Happiness' in Emotional well-being had a large residual covariance with other items and we allowed its residual variance to correlate with 'Calmness', the other positively-phrased item within the same scale (see Figure 1), and inspected a sensitivity model without this item (Section 3.3).

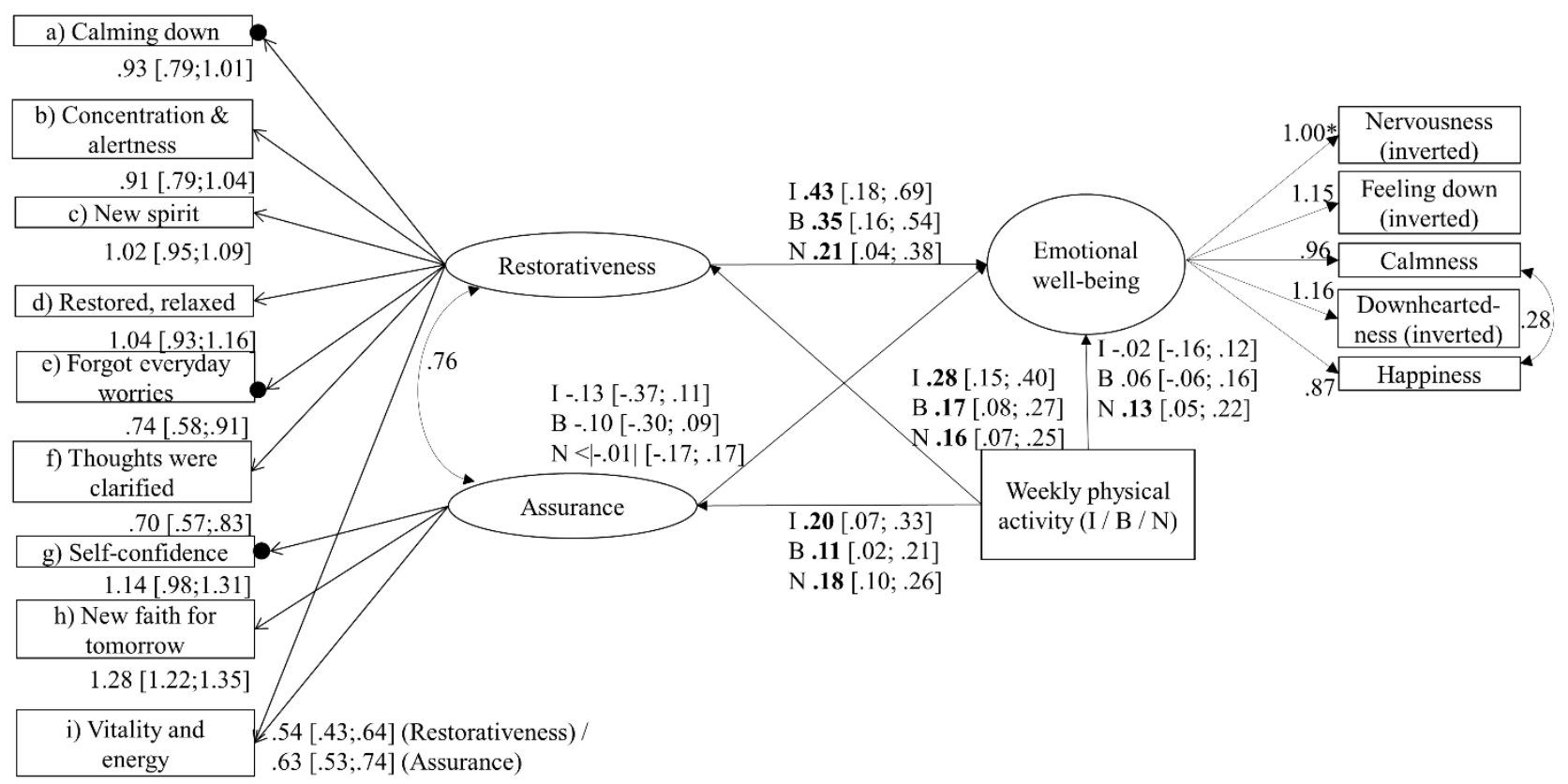

Figure 1 Multigroup exploratory SEM model estimates (standardised with 99\% CIs) for the relationships between Emotional well-being, Restorativeness and Assurance, and frequency of physical activity in indoor (I), built outdoor (B) and natural outdoor (N) environments. $\chi^{2}=964.4$, 
$\mathrm{df}=291, p<.001 ; \mathrm{RMSEA}=.05 ; \mathrm{CFI}=.96 ; \mathrm{TLI}=.96 ;$ SRMR=.05. Black dot: between-group intercepts vary. For simplicity, only (unstandardised) loadings $>.50$ shown. *constrained to 1 .

Regarding differences in means between the groups, Emotional well-being and Assurance were equal (Table 4). The weekly frequency of physical activity was equal in nature (1.24 times; 99\% CI [1.15; 1.32]) and indoors (1.31 [1.2; 1.43]) but significantly lower in built outdoor settings (.99 [.89; 1.08]). Contrary to the measurement invariance model, Restorativeness was greater after physical activity in natural settings than indoors but not built outdoor settings (Table 4). These differences from the previous model are most likely due to the effect being small, and thus sensitive to even small differences in estimation. With 95\% CIs, Restorativeness was evaluated the greatest after physical activity in nature in both models.

Table 4 Estimated factor means, mediations from weekly frequency of physical activity to emotional well-being) and explained variances of the model testing the "repeated restoration" hypothesis (Figure 1). Estimates in bold face: $p<.01$.

\begin{tabular}{|c|c|c|c|c|}
\hline & & Mean $[99 \% \mathrm{CI}]$ & $\begin{array}{c}\text { (Standardised) indirect connection to } \\
\text { emotional well-being [99\% CI] }\end{array}$ & $\begin{array}{l}\mathrm{R}^{2} \\
(\%)\end{array}$ \\
\hline \multirow[t]{3}{*}{ Restorativeness } & Indoor & $0 *$ & $\mathbf{. 1 2}[.03 ; .21]$ & 7.6 \\
\hline & $\begin{array}{l}\text { Built } \\
\text { outdoor }\end{array}$ & $.16[-.10 ; .42]$ & $.06[.02 ; .10]$ & 3.0 \\
\hline & Nature & $.31[.06 ; .56]$ & $.03[-.001 ; .07]$ & 2.5 \\
\hline \multirow[t]{3}{*}{ Assurance } & Indoor & $0 *$ & $-.03[-.08 ; .03]$ & 3.9 \\
\hline & $\begin{array}{l}\text { Built } \\
\text { outdoor }\end{array}$ & $.06[-.19 ; .31]$ & $-.01[-.04 ; .01]$ & 1.3 \\
\hline & Nature & $.07[-.17 ; .32]$ & $<.001[-.03 ; .03]$ & 3.2 \\
\hline \multirow{3}{*}{$\begin{array}{l}\text { Emotional well- } \\
\text { being }\end{array}$} & Indoor & $0 *$ & & 11.4 \\
\hline & $\begin{array}{l}\text { Built } \\
\text { outdoor }\end{array}$ & $.05[-.14 ; .24]$ & & 8.3 \\
\hline & Nature & $.00[-.18 ; .18]$ & & 6.8 \\
\hline
\end{tabular}

* Constrained for model identification

\subsection{Sensitivity analyses}

None of the sensitivity models showed substantial differences to the reported model. We provide the estimates for Sensitivity model 4 (with socio-demographic covariates) in Appendix Figure C.1 and Table C.1 as they may be useful for future research on confounders in people-environment studies. 


\section{Discussion and conclusions}

\subsection{Discussion and limitations}

Our first main result was that not all aspects of recalled restoration were rated greater after physical activity in natural settings compared with indoor and built outdoor environments. Assurance was rated equal in all settings, and items measuring self-confidence and forgetting everyday worries were felt most strongly after physical activity indoors. One possible explanation for these results may derive from different types of activities. Indoor settings may support purposeful activities where monitoring one's personal development is straightforward, potentially leading to increased self-confidence. For example, at the gym people inevitably know how heavy weights they are lifting, whereas during a nature walk they do not need to monitor their performance or progress (unless they wish to). The idea that indoor environments may serve different needs than outdoor environments is in line with Mitchell's results (2013). These results encourage further examination of restorative qualities of built indoor and outdoor environments.

The second main result agrees with a long line of experimental research supporting the restorative role of natural environments (Hartig et al., 2014). The level of Restorativeness (corresponding to the original, 6-item Restoration Outcome Scale) after everyday physical activity was slightly greater when conducted in natural settings than in indoor or built outdoor environments, even when the activity and its setting had been (presumably) freely chosen. This result accords with the metaanalyses comparing natural outdoor environments to indoor and/or built outdoor environments (Bowler et al., 2010; Thompson Coon et al., 2011). What our study adds to the discussion is that the restorative qualities of physical activity in natural settings are not solely due to biases in experimental research such as choosing an unpleasant built comparison setting.

Our third main finding was that the 'repeated restoration' hypothesis was supported in all settings: experiencing greater Restorativeness was connected equally strongly to increased emotional wellbeing in all three settings when controlling for the frequency of physical activity in the respective setting. However, an interesting detail was that only in the 'natural environment' group was the relationship between weekly physical activity and emotional well-being significantly positive, that is, not fully explained by Restorativeness. This finding suggests that other factors beyond restoration explain the positive association between repeated physical activity in natural settings and emotional well-being (Pasanen et al., 2014). At this point, we can only speculate what these may be. Alternatives identified in earlier research specific to natural environments include social aspects, differences in exposure duration (White et al., 2013), identity-related reasons such as nature- 
connectedness (Morton et al., 2017), environmental qualities that support well-being (van den Berg et al., 2015), psychological factors such as motives and the focus of attention (Pasanen et al., 2017) and positive emotional responses other than restoration (Richardson, McEwan, Maratos, \& Sheffield, 2016).

Regarding the psychometric properties of the 9-item Restoration Outcome Scale, the present data supported using the original six items as one factor (in line with Korpela et al., 2008) and two of the additional items as another, indicating assurance. The third additional item, increased vitality and energy, added ambiguity in the scale because it was not clearly part of either factor, and was probably one reason for the strong correlation between the two factors. Prospective studies might consider removing this item from the scale. Nevertheless, the results encourage further use of measurement invariance testing for evaluating the quality and quantity of restoration after visiting different types of settings. In this study, we could infer that the items in the 9-item Restoration Outcome Scale correlate similarly regardless of the type of setting but that not all item means are equal. These item-level differences may be useful for highlighting the benefits of physical activity in other than natural settings. For example, the idea of gaining self-confidence is a novel example of psychological “capacity building” in people-environment studies (Markevych et al., 2017), worth further investigation.

It is evident that this study had some weaknesses. First, the information about the bouts of physical activity that the restoration evaluations were based on were limited to the type of setting. More specific information such as duration (White et al., 2013), company (White et al., 2013), level of physical strain (Fox, 1999), experienced stress (Ulrich, 1983), season and weather would have been useful to include in the analyses. Second, the study was cross-sectional and all results were based on correlations, not causalities. Third, self-reports on physical activity are generally overestimated compared with objective measures, which may have caused some bias in the analyses (Hagstromer, Ainsworth, Oja, \& Sjostrom, 2010). Nevertheless, subjective and objective measures generally correlate moderately, and the tendency to exaggerate the frequency of physical activity is similar in different demographic groups (Hagstromer et al., 2010) and probably also in the different environments used in this study. Fourth, the restoration evaluations were based on single bouts of physical activity and we do not know how well they reflected the respondents' "average" restorative experiences, which may cause some bias when we assess their relationship with emotional wellbeing. Future studies could assess restoration after physical activity repeatedly to avoid this potential bias. Fifth, the environmental categories were quite broad and based on subjective evaluations. Using a single term "natural” to describe the variety of different scenery containing 
little-to-no man-made features has been criticised (Markevych et al., 2017), and the same applies to grouping all indoor and built outdoor environments into one category. This categorisation is, nevertheless, in line with existing research (Bowler et al., 2010, Thompson Coon et al., 2011), and our population-level data enabled exploring broader trends within a wide range of respondents, environments and activities.

\subsection{Conclusions}

We examined whether recalled restoration after everyday physical activity in indoor, built outdoor and natural settings varies in quantity and quality, and how recalled restoration is connected to emotional well-being. The results corroborate experimental studies reporting that natural environments bring an added value to the known benefits of physical activity for mood and wellbeing (Bowler et al., 2010, Thompson Coon et al., 2011). However, indoor environments provided greater benefits for self-confidence and forgetting everyday worries than built or natural outdoor settings. Regardless of the type of environment, greater recalled restoration was connected to greater emotional well-being. This 'repeated restoration' hypothesis was thus not specific to natural environments, and moreover, recalled restoration did not explain the association between regular PA in natural settings and well-being.

The processes leading from momentary restoration to more general emotional well-being merit further research. In the everyday context, examining these associations with longitudinal designs such as diary studies could further our understanding of the interplay between well-being and restoration in specific settings. Such designs could also easily take into account more detailed information about the bouts of physical activity that have tentatively been shown to play a role in restoration evaluations, such as company, activity and duration (White et al., 2013). Our study was a preliminary effort to investigate nuanced differences in recalled restoration after everyday physical activity in different types settings. We call for future research to replicate these findings and to continue exploring the restorative qualities of physical activity in all kinds of spaces, built and natural, in greater detail.

Acknowledgements: We are grateful for Marjo Neuvonen and Tuija Sievänen (Natural Resources Institute Finland) for collaboration in the research project.

Funding: This work was supported by the Academy of Finland [grant number 2501255431]; Finnish Ministry of Education and Culture and Ministry of the Environment [YTA022 and OKM/75/626/2017]; Natural Resources Institute Finland [41007-00073400]; and Kone Foundation [085144]. 
Declarations of interest: none

\section{References}

Aalto, A., Aro, A., \& Teperi, J. (1999). RAND-36 as a measure of health-related quality of life. Reliability, construct validity and reference values in the Finnish general population. [RAND36 terveyteen liittyvän elämänlaadun mittarina: mittarin luotettavuus ja suomalaiset väestöarvot]. Helsinki: Stakes.

Asparouhov, T., \& Muthén, B. (2009). Exploratory structural equation modeling. Structural Equation Modeling: A Multidisciplinary Journal, 16(3), 397-438. doi:10.1080/10705510903008204

Barton, J., \& Pretty, J. (2010). What is the best dose of nature and green exercise for improving mental health? A multi-study analysis. Environmental Science \& Technology, 44(10), 39473955. doi:10.1021/es903183r

Bowler, D., Buyung-Ali, L., Knight, T., \& Pullin, A. (2010). A systematic review of evidence for the added benefits to health of exposure to natural environments. BMC Public Health, 10, 456465. doi:10.1186/1471-2458-10-456

Chen, F. (2007). Sensitivity of goodness of fit indexes to lack of measurement invariance. Structural Equation Modeling: A Multidisciplinary Journal, 14(3), 464-504. doi:10.1080/10705510701301834

Cheung, G., \& Rensvold, R. (2002). Evaluating goodness-of-fit indexes for testing measurement invariance. Structural Equation Modeling, 9(2), 233-255.

Davidov, E., Meuleman, B., Cieciuch, J., Schmidt, P., \& Billiet, J. (2014). Measurement equivalence in cross-national research. Annual Review of Sociology, 40.

Ferguson, C. J. (2009). An effect size primer: A guide for clinicians and researchers. Professional Psychology: Research and Practice, 40(5), 532.

Fox, K. R. (1999). The influence of physical activity on mental well-being. Public Health Nutrition, 2(3a), 411-418. 
Hagstromer, M., Ainsworth, B. E., Oja, P., \& Sjostrom, M. (2010). Comparison of a subjective and an objective measure of physical activity in a population sample. Journal of Physical Activity and Health, 7(4), 541-550. doi:10.1123/jpah.7.4.541

Hartig, T., Lindblom, K., \& Ovefelt, K. (1998). The home and near-home area offer restoration opportunities differentiated by gender. Scandinavian Housing and Planning Research, 15(4), 283-296.

Hartig, T., Mitchell, R., de Vries, S., \& Frumkin, H. (2014). Nature and health. Annual Review of Public Health, 35(1), 207-228. doi:10.1146/annurev-publhealth-032013-182443.

Hays, R., Sherbourne, C., \& Mazel, R. (1993). The rand 36-item health survey 1.0. Health Economics, 2(3), 217-227. doi:10.1002/hec.4730020305

Hine, D., Corral-Verdugo, V., Bhullar, N., \& Frias-Armenta, M. (2016). Advanced statistics for Environment-Behavior research. In R. Gifford (Ed.), Research methods for environmental psychology (pp. 369-388). Chichester, UK: Wiley Online Library.

Hug, S., Hartig, T., Hansmann, R., Seeland, K., \& Hornung, R. (2009). Restorative qualities of indoor and outdoor exercise settings as predictors of exercise frequency. Health \& Place, 15(4), 971-980. doi:10.1016/j.healthplace.2009.03.002

Husu, P., Paronen, O., Suni, J., \& Vasankari, T. (2011). Suomalaisten fyysinen aktiivisuus ja kunto 2010: Terveyttä edistävän liikunnan nykytila ja muutokset [Physical activity and fitness of Finns in 2010: Current status and changes in health-enhancing physical activity]. Opetus- ja kulttuuriministeriön julkaisuja 2011:15.

Kaplan, R., \& Kaplan, S. (1989). The experience of nature: A psychological perspective. Cambridge: Cambridge University Press.

Kaplan, S. (1995). The restorative benefits of nature: Toward an integrative framework. Journal of Environmental Psychology, 15(3), 169-182. doi:10.1016/0272-4944(95)90001-2.

Karmanov, D., \& Hamel, R. (2008). Assessing the restorative potential of contemporary urban environment(s): Beyond the nature versus urban dichotomy. Landscape and Urban Planning, 86(2), 115-125. doi:10.1016/j.landurbplan.2008.01.004 
Kline, R. (2016). Principles and practice of structural equation modeling (4th ed.). New York: Guilford Press.

Korpela, K., Borodulin, K., Neuvonen, M., Paronen, O., \& Tyrväinen, L. (2014). Analyzing the mediators between nature-based outdoor recreation and emotional well-being. Journal of Environmental Psychology, 37(0), 1-7. doi:10.1016/j.jenvp.2013.11.003

Korpela, K. (1992). Adolescents' favourite places and environmental self-regulation. Journal of Environmental Psychology, 12(3), 249-258.

Korpela, K., Ylén, M., Tyrväinen, L., \& Silvennoinen, H. (2008). Determinants of restorative experiences in everyday favorite places. Health \& Place, 14(4), 636-652. doi:10.1016/j.healthplace.2007.10.008

Korpela, K., \& Ylén, M. (2009). Effectiveness of favorite-place prescriptions: A field experiment. American Journal of Preventive Medicine, 36(5), 435-438. doi:10.1016/j.amepre.2009.01.022

McAllister, E., Bhullar, N., \& Schutte, N. S. (2017). Into the woods or a stroll in the park: how virtual contact with nature impacts positive and negative affect. International journal of environmental research and public health, 14(7), 786. doi:10.3390/ijerph14070786

Markevych, I., Schoierer, J., Hartig, T., Chudnovsky, A., Hystad, P., Dzhambov, A. M., ... Fuertes, E. (2017). Exploring pathways linking greenspace to health: Theoretical and methodological guidance. Environmental Research, 158, 301-317. doi:10.1016/j.envres.2017.06.028

Marsh, H., Lüdtke, O., Nagengast, B., Morin, A. J., \& Von Davier, M. (2013). Why item parcels are (almost) never appropriate: Two wrongs do not make a right-Camouflaging misspecification with item parcels in CFA models. Psychological Methods, 18(3), 257. doi:10.1037/a0032773

Morton, T., van der Bles, A., \& Haslam, S. (2017). Seeing our self reflected in the world around us: The role of identity in making (natural) environments restorative. Journal of Environmental Psychology, 49, 65-77.

Muthén, L. K., \& Muthén, B. O. (2012). Mplus user's guide (7th ed.) 
Pasanen, T., Neuvonen, M., \& Korpela, K. (2017). The psychology of recent nature visits: (How) are motives and attentional focus related to post-visit restorative experiences, creativity, and emotional well-being? Environment and Behavior, doi:10.1177/0013916517720261

Pasanen, T., Tyrväinen, L., \& Korpela, K. (2014). The relationship between perceived health and physical activity indoors, outdoors in built environments, and outdoors in nature. Applied Psychology: Health and Well-Being, 6(3), 324-346. doi:10.1111/aphw.12031

Penedo, F., \& Dahn, J. (2005). Exercise and well-being: A review of mental and physical health benefits associated with physical activity. Current Opinion in Psychiatry, 18(2), 189-193.

Richardson, M., McEwan, K., Maratos, F., \& Sheffield, D. (2016). Joy and calm: How an evolutionary functional model of affect regulation informs positive emotions in nature. Evolutionary Psychological Science, 2(4), 308-320. doi:10.1007/s40806-016-0065-5

Rutkowski, L., \& Svetina, D. (2014). Assessing the hypothesis of measurement invariance in the context of large-scale international surveys. Educational and Psychological Measurement, 74(1), 31-57. doi:10.1177/0013164413498257

Ryan, R., Weinstein, N., Bernstein, J., Brown, K., Mistretta, L., \& Gagné, M. (2010). Vitalizing effects of being outdoors and in nature. Journal of Environmental Psychology, 30(2), 159-168. doi:10.1016/j.jenvp.2009.10.009

San Juan, C., Subiza-Pérez, M., \& Vozmediano, L. (2017). Restoration and the city: The role of public urban squares. Frontiers in Psychology. doi:810.3389/fpsyg.2017.02093

Satorra, A. (1999). Scaled and adjusted restricted tests in multi sample analysis of moment structures. SSRN Electronic Journal. doi:10.2139/ssm.189431

Sievänen, T., \& Neuvonen, M. (2011). Luonnon virkistyskäytön kysyntä 2010 ja kysynnän muutos [Outdoor recreation demand 2010 and changes in the demand]. In T. Sievänen, \& M. Neuvonen (Eds.), Luonnon virkistyskäyttö 2010 [Outdoor recreation 2010] (pp. 37-73). Vantaa: Metsäntutkimuslaitos.

Staats, H., Kieviet, A., \& Hartig, T. (2003). Where to recover from attentional fatigue: An expectancy-value analysis of environmental preference. Journal of Environmental Psychology, 23(2), 147-157. 
Stigsdotter, U. K., Corazon, S. S., Sidenius, U., Kristiansen, J., \& Grahn, P. (2017). It is not all bad for the grey city - A crossover study on physiological and psychological restoration in a forest and an urban environment. Health \& Place, 46, 145-154.

doi:10.1016/j.healthplace.2017.05.007

Thompson Coon, J., Boddy, K., Stein, K., Whear, R., Barton, J., \& Depledge, M. (2011). Does participating in physical activity in outdoor natural environments have a greater effect on physical and mental wellbeing than physical activity indoors? A systematic review. Environmental Science \& Technology, 45(5), 1761-1772. doi:10.1021/es102947t

van den Berg, M., Wendel-Vos, W., van Poppel, M., Kemper, H., van Mechelen, W., \& Maas, J. (2015). Health benefits of green spaces in the living environment: A systematic review of epidemiological studies. Urban Forestry \& Urban Greening, 14(4), 806-816. doi:10.1016/j.ufug.2015.07.008

Virtanen, V., Nyberg, R., Salonen, R., Neuvonen, M., \& Sievänen, T. (2011). LVVI 2 seurantatutkimuksen aineisto ja menetelmät [The data and methods of the LVVI2 follow-up survey]. In T. Sievänen, \& M. Neuvonen (Eds.), Luonnon virkistyskäyttö 2010 [Outdoor recreation 2010] (pp. 19-36). Vantaa: Metsäntutkimuslaitos.

White, M., Pahl, S., Ashbullby, K., Herbert, S., \& Depledge, M. (2013). Feelings of restoration from recent nature visits. Journal of Environmental Psychology, 35, 40-51. doi:10.1016/j.jenvp.2013.04.002

Williams, L., \& O'Boyle, E. (2008). Measurement models for linking latent variables and indicators: A review of human resource management research using parcels. Human Resource Management Review, 18(4), 233-242. doi:10.1016/j.hrmr.2008.07.002 


\section{Appendix A}

Table A.1 Estimated correlations (lower diagonal) and correlation residuals (upper diagonal) of the partial measurement invariance model in Step 4. In bold: large covariance residual in at least one group (normalised value $>|1.96|$ ).

a) I calmed down

b) My concentration and $.57 / .64 /$

alertness increased

c) I gained new spirit for $.60 / .62$

my everyday routines

d) I restored and relaxed

e) I forgot everyday

worries

f) My thoughts were

clarified

g) I became more self-

confident

h) I gained faith in

tomorrow

i) My vitality and

energy increased
$.60 / .68 / .67 / .70 /$

$$
\begin{gathered}
b \\
.15 / .06 / \\
.06
\end{gathered}
$$

.66

$.58 / .68 /$

.70

.66

$.48 / .55 /$

.53

$.65 / .71$

$.57 / .63 /$

$.54 / .58 /$

.62

$.64 / .67 /$

.52
.52

$.50 / .55 /$

.55

$.58 / .63 /$

.61
.69

.57

.67

$56 / .58 /$

.58

$.58 / .60 /$

.61

$.68 / .75 /$

$$
.74
$$

$.56 / .61 /$

$$
.60
$$

$.67 / .70 /$

$$
.70
$$

.58 / .60 /

.60

$.60 / .63 /$

.63

.66

.69
$.68 / .70 /$

$$
\begin{gathered}
\mathrm{d} \\
.06 /-.01 / \\
.01 \\
.02 /-.04 /- \\
.05 \\
.01 / .00 / \\
.01 \\
\\
.54 / .61 / \\
.60 \\
.64 / .70 / \\
.69 \\
.54 / .59 / \\
.58 \\
.56 / .61 / \\
.60 \\
.65 / .70 /
\end{gathered}
$$$$
\begin{array}{cc}
\mathrm{e} & \mathrm{d} /-.01 / \quad-.01 /-.05 /
\end{array}
$$$$
.02 /-.04 /-\quad-.04 /-.03 /
$$$$
-.04
$$$$
\text { / - } .06
$$$$
-.03
$$$$
.05 /-.03 /
$$$$
.03
$$

.68

$.56 / .60 /$

.60

$.53 / .57 /$

.56

$.56 / .59 /$

.59

.59 / .62 /

.60

$$
\begin{array}{cc}
\mathrm{f} & \mathrm{g} \\
.00 /-.01 /- & .04 /-.02 /-
\end{array}
$$$$
.03
$$

.01

$.04 /-.04 /$

$$
.00
$$

$.04 /-.03 /$

$$
.04
$$

$.00 /-.03 /-.03 /-.02 /-$

.01

.01

$.04 /-.04 /-.03 /-.02 /-$

.01

.03
$.10 / .07 /$

.09

$.00 / .00 /$

.01

$.01 / .01 /$

.04

$.65 / .68 /$

.68

$.69 / .71 /$

.72

$.71 / .73 /$

.72
$.80 / .83 /$

.83

$.73 / .74$

.73

$$
\begin{array}{cc}
\mathrm{h} & \mathrm{i} \\
.02 /-.01 / & -.02 /-.07 / \\
.02 & -.02 \\
.01 /-.03 / & -.02 /-.05 /
\end{array}
$$$$
.02 \quad-.02
$$$$
.02 /-.05 / \quad .06 / .02 /
$$

$$
.01 \quad .05
$$$$
.03 /-.03 / \quad-.02 /-.02 /
$$$$
.01 \quad .04
$$

$.01 /-.03 /-.01 /-.04 /-$

$$
.01 \quad .01
$$

$.00 /-.04 / .01 /-.03 /-$

$.00 \quad .01$

$.00 / .00 / .02 /-.01 /-$

.00

.04

$.04 / .01 /-$ .01

$.77 / .78 /$

.77

Note: The analysis is based on covariances but correlations are shown for more intuitive interpretation. In the models, the estimated covariances were constrained to equal across groups but the estimated correlations can differ due to variations in standard deviations between groups. 
Appendix B

Table B.1. Unstandardised path estimates and their standard errors (s.e.) of the model testing the "repeated restoration" hypothesis (Figure 1). Estimates in bold face: $p<.01$.

\begin{tabular}{|c|c|c|c|c|c|c|c|c|c|c|}
\hline & \multicolumn{3}{|c|}{ Emotional well-being } & \multicolumn{3}{|c|}{ Factor 1 Restorativeness } & \multicolumn{3}{|c|}{ Factor 2 Assurance } \\
\hline & & Indoor & $\begin{array}{c}\text { Built } \\
\text { outdoor }\end{array}$ & Nature & Indoor & $\begin{array}{l}\text { Built } \\
\text { outdoor }\end{array}$ & Nature & Indoor & $\begin{array}{c}\text { Built } \\
\text { outdoor }\end{array}$ & Nature \\
\hline Factor 1 & & 0.31 & 0.23 & 0.14 & & & & & & \\
\hline Restorativeness & s.e. & 0.07 & 0.05 & 0.05 & & & & & & \\
\hline Factor 2 & $\mathrm{~b}$ & -0.1 & -0.07 & 0 & & & & & & \\
\hline Assurance & s.e. & 0.07 & 0.05 & 0.04 & & & & & & \\
\hline Frequency of & $\mathrm{b}$ & -0.02 & 0.04 & 0.08 & 0.27 & 0.18 & 0.15 & 0.19 & 0.12 & 0.17 \\
\hline PA & s.e. & 0.04 & 0.03 & 0.02 & 0.05 & 0.04 & 0.03 & 0.05 & 0.04 & 0.03 \\
\hline
\end{tabular}


Appendix C Sensitivity model 4

Figure C.1 Sensitivity model 4, with socio-demographic covariates $(n=2211)$. Standardised estimates and 99\% CIs in indoor (I), built outdoor (B), and natural outdoor (N) environments. For gender, only the outcome standardised. $\chi^{2}=1267.49, d f=405, p<.001, \mathrm{RMSEA}=.054, \mathrm{CFI}=.946$, TLI=.941, SRMR=.056. For simplicity, the factor items not shown (similar to Fig. 1). $\mathrm{R}^{2}$ (\%): Restorativeness 11.2 / 6.0 / 7.5; Assurance 4.2 / 2.2 / 5.1; Emotional well-being 16.2 / 16.2 / 12.8, respectively.

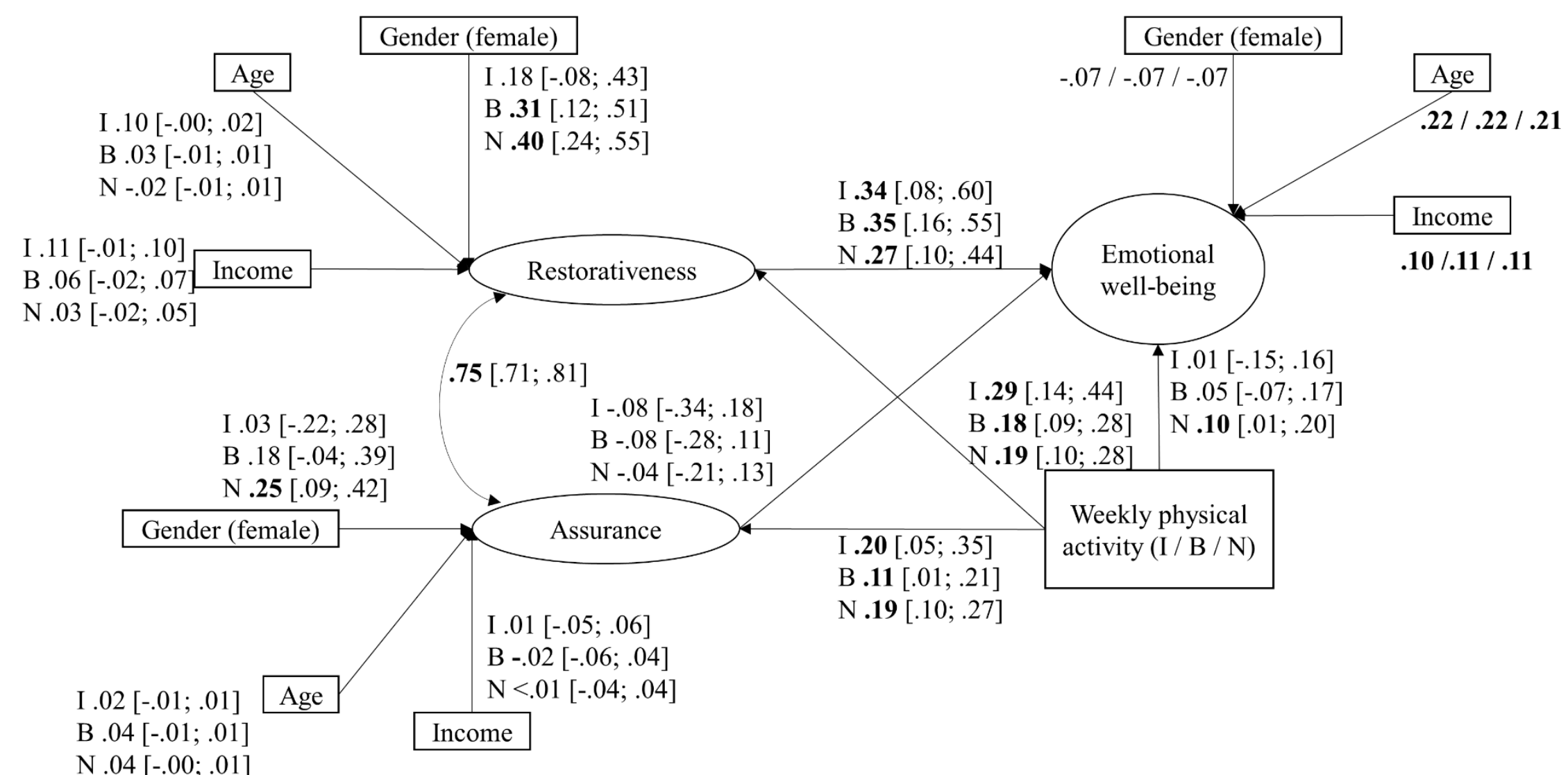


Table C.1 Unstandardised path estimates and their standard errors (s.e.) of Sensitivity model 4 with socio-demographic covariates (Figure C.1). Estimates in bold face: $p<.01$.

\begin{tabular}{|c|c|c|c|c|c|c|c|c|c|c|}
\hline & & \multicolumn{3}{|c|}{ Emotional well-being } & \multicolumn{3}{|c|}{ Factor 1 Restorativeness } & \multicolumn{3}{|c|}{ Factor 2 Assurance } \\
\hline & & Indoor & $\begin{array}{c}\text { Built } \\
\text { outdoor }\end{array}$ & Nature & Indoor & $\begin{array}{c}\text { Built } \\
\text { outdoor }\end{array}$ & Nature & Indoor & $\begin{array}{c}\text { Built } \\
\text { outdoor }\end{array}$ & Nature \\
\hline Factor 1 & $\mathrm{~b}$ & .24 & .23 & .18 & & & & & & \\
\hline Restorativeness & s.e. & .07 & .05 & .05 & & & & & & \\
\hline Factor 2 & $\mathrm{~b}$ & -.06 & -.06 & -.03 & & & & & & \\
\hline Assurance & s.e. & .07 & .05 & .05 & & & & & & \\
\hline Frequency of & $\mathrm{b}$ & .01 & .03 & .07 & .29 & .19 & .18 & .20 & .12 & .18 \\
\hline physical activity & s.e. & .04 & .03 & .02 & .06 & .04 & .04 & .06 & .04 & .03 \\
\hline Gender(female) & $\mathrm{b}$ & & $-.05^{\mathrm{a}}$ & & .19 & .32 & .41 & .03 & .18 & .26 \\
\hline & s.e. & & .03 & & .11 & .08 & .07 & .10 & .08 & .07 \\
\hline Age & b & & $.01^{a}$ & & .01 & $<.01$ & $<.01$ & $<.01$ & $<.01$ & $<.01$ \\
\hline & s.e. & & $<.01$ & & $<.01$ & $<.01$ & $<.01$ & $<.01$ & $<.01$ & $<.01$ \\
\hline Income & b & & $.03^{\mathrm{a}}$ & & .05 & .03 & .01 & .01 & -.01 & $<.01$ \\
\hline (thousands) & s.e. & & .01 & & .02 & .02 & .01 & .02 & .02 & .01 \\
\hline
\end{tabular}

a Estimate constrained to equal across the groups 